\title{
ESPAÇAMENTO, DENSIDADE POPULACIONAL E ADUBAÇÃO NITROGENADA NA CULTURA DO MILHO(1) $^{(1)}$
}

\author{
J osé Pedro Ribeiro do Amaral Filho(2), D. Fornasieri Filho(3), \\ Rogerio Farinelli(2) \& J osé Carlos Barbosa(4)
}

\begin{abstract}
RESUMO
A distribuição espacial de plantas por área é um recurso para aumentar a produtividade. Para materiais de alta produtividade, são necessárias mais informações quanto à resposta à adubação nitrogenada. Assim, avaliou-se na cultura do milho a influência do espaçamento, da densidade populacional e de doses de nitrogênio no teor de nitrogênio nas folhas, estimativa do teor de clorofila, número de grãos por espiga, massa de $\mathbf{1 . 0 0 0}$ grãos, produtividade e teor de proteína nos grãos. O trabalho foi instalado no ano agrícola 2000/2001 e constou de tratamentos representados pela combinação de dois espaçamentos entre as linhas $(0,80$ e $0,60 \mathrm{~m})$ com três densidades populacionais $(40,60$ e 80.000 plantas ha-1) e quatro doses de nitrogênio em cobertura $(0,50,100$ e $150 \mathrm{~kg} \mathrm{ha}^{-1} \mathrm{~N}$ ). $\mathrm{O}$ aumento na doses de $\mathrm{N}$ em cobertura promoveram acréscimo no teor de $\mathbf{N}$ foliar, na estimativa do teor de clorofila, no número de grãos por espiga, na massa de $\mathbf{1 . 0 0 0}$ grãos, na produtividade e no teor de proteína nos grãos de milho. A maior produtividade de grãos foi obtida de acordo com as doses crescentes de $\mathbf{N}$ em cobertura juntamente com o espaçamento entre as linhas de 0,80 m e 80.000 plantas ha-1.
\end{abstract}

Termos de indexação: Zea mays (L.), clorofila, nitrogênio, produtividade.

\section{SUMMARY: ROW SPACING, POPULATION DENSITY AND NITROGEN FERTILIZATION IN MAIZE}

Thealteration of spatial distribution of plants is an option to increase the grain yield. For high-yiel ding materials more information about the influence of nitrogen fertilization is needed. Thus, the influence of row spacing, population densities and nitrogen rates on

\footnotetext{
(1) Parte da Tese de Mestrado do primeiro autor apresentada à F aculdade Ciências Agrárias eVeterinária - FCAV/UNESP , J aboticabal (SP). Recebido para publicação em julho de 2003 e aprovado em março de 2005.

(2) Doutorando do Departamento de Produção Vegetal da Faculdade Ciências Agrárias e Veterinária - FCAV/UNESP. CEP 18603970 Botucatu (SP). E-mails: josepedro@fca.unesp.br, rfarinelli@fca.unesp.br

(3) Professor do Departamento de Produção Vegetal, FCAV/UNESP. E-mail: fornasieri @fcav.unesp.br

(4) Professor do Departamento de Ciências Exatas, FCAV/UNESP. E-mail: jcbarbosa@fcav.unesp.br
} 


\begin{abstract}
the leaf nitrogen concentration, estimated concentration of chlorophyll, number of grains per ear, mass of thousand grains, grain yield, and protein content were evaluated. This study was carried out in the 2000/ 2001growth season; thetreatments weretwo row spacings ( 0.60 and $0.80 \mathrm{~m}$ ); three population densities $\left(40,000,60,000\right.$ and 80,000 plants ha $\left.{ }^{-1}\right)$ and four nitrogen rates $\left(0,50,100\right.$, and $\left.150 \mathrm{~kg} \mathrm{ha}^{-1} \mathrm{~N}\right)$. I ncreased nitrogen rates in top dressing led to a increase in the leaf nitrogen and estimated chlorophyll concentration, number of grains per ear, mass of thousand grains, grain yield and protein content of grains. Higher grain yied d was achieved with increasing top dressed $\mathrm{N}$ rates in combination with a $0.80 \mathrm{~m}$ row spacing and a plant density of 80.000 plants ha-1.
\end{abstract}

Index terms: Zea mays (L.), chlorophyll, nitrogen, yield.

\section{NTRODUÇÃO}

Com o acréscimo na densidade de plantas e redução do espaçamento entre linhas de semeadura, é possível otimizar a eficiência da interceptação de luz pelo aumento do índice fol iar mesmo nos estádios fenológicos iniciais, melhorando o aproveitamento de água e nutrientes, reduzindo a competição inter e intra-específica por esses fatores, aumentando a matéria seca e a produção de grãos (Molin, 2000).

A população ideal depende do cultivar, da fertilidade do solo, da disponibilidade hídrica e da época de semeadura. Desse modo, a produtividade tende a se el evar com o aumento da população, até atingir determinado número de plantas por área, queé considerada como população ótima. Após esse ponto, a produtividade decresce com o aumento do número de plantas por área. Quando a densidade de plantas é baixa, ocorre certa compensação por meio do aumento no número de espigas, em razão da prolificidade do genótipo e, ou, variação no tamanho da espiga, o que pode minimizar a diferença da produtividade (Pereira, 1991).

Para que possa expressar todo seu potencial produtivo, a cultura do milho requer que suas exigências nutricionais sejam plenamenteatendidas, em virtude da grande extração de nutrientes do solo. Nesse sentido, o nitrogênio é o nutriente exigido em maior quantidade pela cultura, variando as recomendações da adubação nitrogenada em cobertura em cultivo de sequeiro para altas produtividades de 50 a $90 \mathrm{~kg} \mathrm{ha}^{-1}$ de $\mathrm{N}$ e, para cultivo irrigado, de 120 a $150 \mathrm{~kg} \mathrm{ha}^{-1}$ (Souza et al., 2003).

Segundo Piekielek et al. (1995), oteor declorofila na folha pode ser utilizado para predizer o nível nutricional de nitrogênio nas plantas, pelo fato dea quantidade desse pigmento correlacionar-se positivamente com o teor de $\mathrm{N}$ na planta. Argenta et al. (2000b) relataram ser vantajoso o método de leitura de clorofila, uma vez que pode ser efetuado em poucos minutos, possibilitando rápidos diagnósticos da situação da lavoura. Além disso, os custos de operação são mínimos, ao contrário de outros testes que exigem a compra sistemática de produtos químicos, já que não há necessidade de envio de amostras para laboratório, com economia de tempo e dinheiro, e o agricultor pode analisar quantas amostras for preciso, sem implicar destruição de folhas.

A adubação nitrogenada influi positivamente na produtividade de grãos da cultura do milho, como também aumenta o índice de área foliar, massa de 1.000 grãos, altura de plantas, rendimento de biomassa eíndicedecol heita (Ulger et al., 1987; Büll, 1993). Os fatores que contribuem para o aumento na produtividade, coma el evação das doses denitrogênio, são representados pelo acréscimo no número de espigas e aumento no peso das espigas (Duriex et al., 1993).

Desse modo, o objetivo deste trabal ho foi avaliar a influência de espaçamentos entre linhas, densidades populacionais e adubação nitrogenada em cobertura na nutrição da planta e produtividade da cultura de milho.

\section{MATERIAL E MÉTODOS}

O experimento foi instalado na Faculdade de Ciências Agrárias e Veterinárias/UNESP, campus de J aboticabal, localizada a 21 o $15^{\prime}$ ' 22 " S a 48 o 18 ' 58 " W e altitude de $575 \mathrm{~m}$. O clima da região é do tipo Cwa, sendo o mês mais quente o de janeiro $\left(24,2^{\circ} \mathrm{C}\right)$ e os mais frios os de junho e julho $\left(17,9{ }^{\circ} \mathrm{C}\right)$, apresentando preci pitação média anual de 1.435 mm (André \& Volpe, 1982).

O sol o foi classificado como Latossolo VermelhoEscuro distrófico A moderado textura argilosa e relevo suaveondulado (Andriolli \& Centurion, 1999), tendo como resultado da anál ise química na camada de 0-20 cm, segundo Raij \& Quaggio (1983), os valores de $\mathrm{pH}$ em $\mathrm{CaCl}_{2}=6,1 ;$ M.O. $=16 \mathrm{~g} \mathrm{dm}^{-3}$; $\mathrm{P}($ resina $)=30 \mathrm{mg} \mathrm{dm}^{-3} ; \mathrm{K}=2,2 \mathrm{mmol}_{\mathrm{C}} \mathrm{dm}^{-3} ; \mathrm{Ca}=$ $39 \mathrm{mmol}_{\mathrm{c}} \mathrm{dm}^{-3} ; \mathrm{Mg}=31 \mathrm{mmol}_{\mathrm{c}} \mathrm{dm}^{-3} ; \mathrm{H}+\mathrm{Al}=$ $15 \mathrm{mmol}_{\mathrm{C}} \mathrm{dm}^{-3} ; \mathrm{SB}=72,2 \mathrm{mmol}_{\mathrm{C}} \mathrm{dm}^{-3} ; \mathrm{CTC}=$ $87,2 \mathrm{mmol}_{\mathrm{C}} \mathrm{dm}^{-3}$ e $\mathrm{V} \%=83$. Para a extração dos cátions trocáveis ( $\mathrm{K}, \mathrm{Ca}$ e Mg) e acidez potencial $(\mathrm{H}+\mathrm{Al})$, utilizaram-se uma mistura de resina de troca catiônica e aniônica e uma solução de acetato de cál cio $\left(1 \mathrm{~mol} \mathrm{~L}^{-1}\right)$ em $\mathrm{pH}=7,0$, respectivamente. 
O delineamento experimental utilizado foi em bl ocos ao acaso com parcel as subsubdivididas com 4 repetições. As parcelas foram constituídas de dois espaçamentos entre linhas $(0,80$ e $0,60 \mathrm{~m})$; as subparcelas de três densidades populacionais $(40.000,60.000$ e 80.000 plantas ha-1), e as subsubparcelas de quatro doses de nitrogênio em cobertura $\left(0,50,100\right.$ e $150 \mathrm{~kg} \mathrm{ha}^{-1}$ de N). Esta adubação constituiu na aplicação de duas doses iguais: a primeira, no estádio 1 (planta com quatro fol has totalmente desdobradas), e a segunda, no estádio 2 (planta com oito folhas), de acordo com Fancelli (1986), adaptado de Nel \& Smith (1978), tendo como fonte o nitrato de amônio.

As subsubparcelas constituíram-se de oitolinhas com $5 \mathrm{~m}$ de comprimento, sendo as seis linhas centrais consideradas úteis eas demais bordaduras. Utilizou-se o híbrido simples AG 9010 de ciclo precoce, grãos de cor alaranjada, textura semidura, apresentando folhas eretas e resistente ao acamamento.

O experimento foi efetuado no sistema plantio direto, com a área ocupada anteriormente pela cultura de milho. Essa área permaneceu em pousio durante o período de entre safra, sendo efetuada a dessecação com herbicida glyphosate na dose de 5,0 L ha-1 do produto comercial. Posteriormente, realizou-se a adubação no sulco de semeadura, utilizando-se a fórmula comercial 00-20-20, na dose de $300 \mathrm{~kg} \mathrm{ha}^{-1}$. A semeadura foi efetuada manualmente, em 12/12/2001, utilizando um excesso de $50 \%$ de sementes, com posterior desbaste, deixando-se um número de plantas por metro correspondente à densidade populacional do respectivo tratamento.

Para determinar o teor de $\mathrm{N}$ foliar, foram retiradas em cinco plantas decada subparcela a fol ha abaixo e oposta à primeira espiga. Após secagem e moagem, as fol has foram processadas de acordo com o método descrito em Malavolta (1987).

A estimativa do teor de clorofila foi determinada por um medidor portátil Minolta SPAD 502 (Soil Plant Analysis Development), conforme método proposto por Piekielek et al. (1995). As leituras também foram realizadas na fol ha abaixo e oposta à primeira espiga nas subsubparcelas, quando os grãos estavam no ponto em quea linha do leiteencontravase a $1 / 4$ da distância do ápice do grão até a sua base, e efetuadas em 1 a $2 \mathrm{~cm}$ da borda da fol ha eno terço médio da folha.

Determinaram-se o número de grãos por espiga e a massa de 1.000 grãos, esta realizada em doze espigas por subsubparcela, com dados expressos em $13 \%$ de base úmida. A produtividade de grãos foi determinada na área útil de cada subsubparcela, também expressa em $13 \%$ de base úmida. O teor de proteína bruta nos grãos foi avaliado mediantea obtenção do teor de N total dos grãos, multiplicandose o valor pelo fator 6,25 .
A pós a análise de variância e, no caso de haver significância ( $P<0,5)$, os fatores qualitativos foram comparados peloteste de Tukey $(P<0,05)$, enquanto os fatores quantitativos foram submetidos à análise de regressão polinomial.

\section{RESULTADOS E DISCUSSÃO}

Deacordo com Raij et al. (1996), o nível adequado do teor de nitrogênio na folha de milho para um desenvol vimento adequado está situado na faixa de 27,5 a 32,5 g kg-1, portanto, quanto a este el emento, a nutrição foi adequada (Quadro 1 ), não comprometendo o desenvolvimento da cultura. Embora o teor de $\mathrm{N}$ foliar no tratamento sem adubação tenha sido consi derado adequado, o milho respondeu com o aumento na produtividade de grãos à adição de doses desse nutriente (Figura 1e), mesmo com decréscimo na densidade populacional (Quadro 1).

Nota-se, também, que os fatores espaçamento, densidade populacional e adubação nitrogenada resultaram em efeito $(P<0,05)$ na estimativa de clorofila (Quadro 1), respondendo os valores deste parâmetro linearmente às doses de nitrogênio (Figura 1b). Observou-se, ainda, interação para espaçamento $x$ densidade populacional (Quadro 2), com maiores valores da estimativa de cl orofila para o espaçamento de $0,80 \mathrm{~m}$ com a população de 80.000 plantas ha-1. ${ }^{-1}$ O monitoramento do nível adequado de $\mathrm{N}$ na planta surgiu com o objetivo de diagnosticar a necessidade ou não de sua aplicação, visto que a aplicação de altas doses pode ocasionar altas produtividades; no entanto, pode não ser economicamente viável.

Segundo Piekielek et al . (1995), oteor declorofila na fol ha é utilizado para predizer onível nutricional de nitrogênio nas plantas, pel o fato dea quantidade desse pigmento correlacionar-se positivamentecom o teor de N na planta. Argenta et al. (2000a) afirmaram quea leitura realizada com cl or ofilômetro estima com boa precisão o teor de cl orofila nas fol has de milho, sendo o monitoramento do nível de nitrogênio nas plantas eficiente parâmetro para separar plantas com deficiência e com nível adequado desse nutriente.

Em relação ao número de grãos por espiga, houve diferença quanto ao espaçamento entre linhas e densidade populacional. Os menores espaçamentos e a densidade populacional resultaram em valores superiores (Quadro 1), corroborando, em parte, com Penariol et al. (2003), que obtiveram redução no número de grãos por espiga com o aumento na densidade de 40.000 a 80.000 plantas ha-1, com o mesmo cultivar, na safrinha. Isso resulta numa melhor distribuição das plantas na área, possibilitando a maximização da atividade 
Quadro 1. Teor de nitrogênio foliar, estimativa de clorofila, número de grãos por espiga, massa de 1.000 grãos, produtividade de grãos e teor de proteína nos grãos na cultura do milho, conforme o espaçamento entre linhas, densidade populacional e adubação nitrogenada

\begin{tabular}{|c|c|c|c|c|c|c|}
\hline Fonte de variação & $\begin{array}{l}\text { Teor de N } \\
\text { foliar }\end{array}$ & $\begin{array}{l}\text { Estimativa de } \\
\text { clorofila }\end{array}$ & $\begin{array}{l}\text { Grãos por } \\
\text { espiga }\end{array}$ & $\begin{array}{l}\text { Massa de } \\
1.000 \text { grãos }\end{array}$ & $\begin{array}{r}\text { Produtivida } \\
\text { de de grãos }\end{array}$ & $\begin{array}{l}\text { Teor de } \\
\text { Proteína }\end{array}$ \\
\hline Espaçamento entre linhas (m) & $\mathrm{g} \mathrm{kg}^{-1}$ & Unidades SPAD & no & g & $\mathrm{kg} \mathrm{ha}^{-1}$ & $\%$ \\
\hline $\begin{array}{l}0,60 \\
0,80\end{array}$ & $\begin{array}{l}34,0 \mathrm{a} \\
32,0 \mathrm{~b}\end{array}$ & $\begin{array}{l}61,8 \mathrm{~b} \\
63,3 \mathrm{a}\end{array}$ & $\begin{array}{l}515 a \\
506 b\end{array}$ & $\begin{array}{l}347 a \\
347 a\end{array}$ & $\begin{array}{l}8394 a \\
8046 b\end{array}$ & $\begin{array}{l}9,1 \text { a } \\
8,9 a\end{array}$ \\
\hline \multicolumn{7}{|l|}{$\begin{array}{l}\text { Densidade populacional } \\
(\text { plantas ha-1) }\end{array}$} \\
\hline 40.000 & $34,1 \mathrm{a}$ & $62,7 \mathrm{ab}$ & 531 a & $351 \mathrm{a}$ & $6689 c$ & 9,1 a \\
\hline 60.000 & $33,3 a$ & 62,9 a & $510 \mathrm{~b}$ & $345 a$ & $8359 \mathrm{~b}$ & 9,1 a \\
\hline 80.000 & $31,6 \mathrm{~b}$ & $61,9 \mathrm{~b}$ & $490 \mathrm{c}$ & $245 a$ & $9565 a$ & $8,8 \mathrm{a}$ \\
\hline Espaçamento $(E)$ & $34,82^{* *}$ & $21,19^{* *}$ & $5,13^{*}$ & $0,02^{\text {ns }}$ & $13,79^{* *}$ & $0,73^{\text {ns }}$ \\
\hline Densidade (D) & $19,64^{* *}$ & $4,18^{*}$ & $55,4^{*}$ & $2,05^{\text {ns }}$ & $314,44^{* *}$ & $2,42^{\text {ns }}$ \\
\hline Nitrogênio (N) & $36,47^{* *}$ & $47,26^{* *}$ & $35,8^{* *}$ & $26,09^{*}$ & $22,17^{* *}$ & $38,53^{* *}$ \\
\hline$E \times D$ & $2,13^{\text {ns }}$ & $8,14^{* *}$ & $2,21^{\mathrm{ns}}$ & $4,85^{*}$ & $6,28^{* *}$ & $0,29^{\text {ns }}$ \\
\hline $\mathrm{E} \times \mathrm{N}$ & $0,12^{\text {ns }}$ & $0,13^{\text {ns }}$ & $0,12^{\text {ns }}$ & $0,11^{\text {ns }}$ & $0,26^{\text {ns }}$ & $0,84^{\text {ns }}$ \\
\hline $\mathrm{D} \times \mathrm{N}$ & $0,19^{\text {ns }}$ & $1,50^{\text {ns }}$ & $0,70^{\text {ns }}$ & $0,65^{\text {ns }}$ & $0,30^{\text {ns }}$ & $0,85^{\text {ns }}$ \\
\hline$E \times D \times N$ & $0,33^{\text {ns }}$ & $0,33^{\text {ns }}$ & $0,56^{\mathrm{ns}}$ & $0,20^{\text {ns }}$ & $0,47^{n s}$ & $0,46^{\mathrm{ns}}$ \\
\hline C.V. (\%) & 5,03 & 2,48 & 3,04 & 3,87 & 5,59 & 7,14 \\
\hline
\end{tabular}

Obs.: Médias seguidas de letras distintas diferem entre si pelo teste de Tukey a $5 \%$.

ns: não-signficativo, ${ }^{*} \mathrm{e}^{* *}$ significativo a 5 e $1 \%$.

Quadro 2. Estimativa de clorofila, massa de 1.000 grãos e produtividade da cultura do milho, conforme o espaçamento entre linhas $x$ densidade populacional

\begin{tabular}{|c|c|c|c|}
\hline \multirow{2}{*}{ E spaçamento entre linhas } & \multicolumn{3}{|c|}{ Densidade populacional } \\
\hline & 40.000 & 60.000 & 80.000 \\
\hline \multirow[t]{2}{*}{$\mathrm{m}$} & 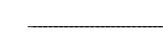 & lantas ha-1 & - \\
\hline & \multicolumn{3}{|c|}{ Estimativa de clorofila (unidades SPAD) } \\
\hline \multirow[t]{2}{*}{$\begin{array}{l}0,60 \\
0,80\end{array}$} & $\begin{array}{l}61,1 \mathrm{Bb} \\
64,3 \mathrm{Aa}\end{array}$ & $\begin{array}{l}62,4 \mathrm{Aa} \\
63,5 \mathrm{Aa}\end{array}$ & $\begin{array}{l}\text { 61,8 Aab } \\
61,9 \mathrm{Ba}\end{array}$ \\
\hline & \multicolumn{3}{|c|}{ Massa de 1.000 grãos, g } \\
\hline \multirow[t]{2}{*}{$\begin{array}{l}0,60 \\
0,80\end{array}$} & $\begin{array}{l}351,5 \mathrm{Aa} \\
350,4 \mathrm{Aa}\end{array}$ & $\begin{array}{l}339,6 \mathrm{Bb} \\
350,0 \mathrm{Aa}\end{array}$ & $\begin{array}{l}350,5 \mathrm{Aab} \\
340,1 \mathrm{Ab}\end{array}$ \\
\hline & \multicolumn{3}{|c|}{ Produtividade de grãos, kg ha-1 } \\
\hline $\begin{array}{l}0,60 \\
0,80\end{array}$ & $\begin{array}{l}6931 \mathrm{Ca} \\
6468 \mathrm{Cb}\end{array}$ & $\begin{array}{l}8343 \mathrm{Ba} \\
8447 \mathrm{Ba}\end{array}$ & $\begin{array}{l}9909 \mathrm{Aa} \\
9223 \mathrm{Ab}\end{array}$ \\
\hline
\end{tabular}

Obs.: Médias seguidas de letras distintas diferem entre si nas linhas (maiúsculas) e na coluna (minúsculas) pelo teste de Tukey a $5 \%$.

fotossintética pós-antese. Segundo Sangoi et al. (2000), as plantas espaçadas eqüi distantes competem minimamente por nutrientes, luz e outros fatores, favorecendo o mel hor desenvol vimento das espigas.

O incremento nas doses de $\mathrm{N}$ também promoveu aumento linear no número de grãos por espiga (Figura 1c), concordando com Escosteguy et al. (1997). Melgar et al. (1991) também obtiveram resultados semelhantes, pois, com o aumento das doses de nitrogênio, de 0 a $120 \mathrm{~kg} \mathrm{ha}^{-1}$, o número de grãos por espiga elevou-se de 75 para 187, resultando numa maior produtividade.
A massa de 1.000 grãos aumentou de forma linear com a adubação nitrogenada (Figura $1 d$ ), havendo interação para espaçamentos $x$ densidades populacionais (Quadro 2), com valor superior para o espaçamento de 0,60 m com 40.000 plantas ha-1. Escosteguy et al. (1997), comparando doses de nitrogênio, que variaram de 0 a $160 \mathrm{~kg} \mathrm{ha}^{-1}$, não obtiveram diferenças com relação a essa variável, tendo apresentado valor médio de $275 \mathrm{~g}$. Contudo, Mel gar et al. (1991) conseguiram incremento linear na massa de grãos de acordo com as doses na variedadeBR 5102, apresentando variação de $260 \mathrm{~g}$ (testemunha) a $277 \mathrm{~g}$ (120 kg ha-1 de N). 
Quanto à produtividade de grãos, verificou-se novamente acréscimo linear com a el evação das doses de nitrogênio (Figura 1e), não concordando com Souza et al. (2003), que não obtiveram resposta na produtividade à aplicação de 0 a $120 \mathrm{~kg} \mathrm{ha}^{-1}$ de $\mathrm{N}$ em cobertura. Também houve efeito $(P<0,05)$ na interação espaçamentos $x$ densidades populacionais (Quadro 2), com maior produtividade mediante o emprego de 0,60 m de espaçamento entre linhas e densidade populacional de 80.000 plantas ha-1, assemel hando-seaos resultados obtidos por Dourado Neto et al. (2003), em trabalho utilizando 0,4 $\mathrm{m}$ e $0,8 \mathrm{~m}$ entre linhas, variando a densidade populacional entre 30.000 a 90.000 plantas ha-1, como também para Penariol et al. (2003), utilizando densidades de 40, 60 e 80.000 plantas ha-1. Porém, Rezende et al. (2003) observaram que o aumento na produtividade de grãos, tanto para o espaçamento entre linhas e, ou, para a melhor densidade de plantas, dependeu das condições climáticas do ano agrícola.

O espaçamento de 0,80 m entre linhas, a densidade populacional de 40.000 plantas ha-1 esem adubação nitrogenada acarretaram a menor produtividade de grãos $\left(6.048 \mathrm{~kg} \mathrm{ha}^{-1}\right)$. Esta produtividade pode ser explicada pela el evada capacidade do solo em fornecer $\mathrm{N}$ para as plantas, bem como pelas adequadas condições climáticas durante o ciclo da cultura. Fornasieri Filho (1992) relatou que, em sol os com disponi bilidade adequada de matéria orgânica e sob a ocorrência favorável de precipitação pluvial, os efeitos da adubação nitrogenada são, via de regra, pouco pronunciados.

$\begin{array}{lll}\text { E1P1 } & \hat{\mathrm{Y}}=30,75+0,036 \mathrm{X} & 0,99 * * \\ \text { E1P2 } & \hat{\mathrm{Y}}=30,31+0,029 \mathrm{X} & 0,98^{* *} \\ \text { E1P3 } & \hat{\mathrm{Y}}=27,48+0,035 \mathrm{X} & 0,99 * * \\ \text { E2P1 } & \hat{\mathrm{Y}}=32,46+0,031 \mathrm{X} & 0,99 * * \\ \text { E2P2 } & \hat{\mathrm{Y}}=31,35+0,037 \mathrm{X} & 0,97 * * \\ \text { E2P3 } & \hat{\mathrm{Y}}=31,35+0,026 \mathrm{X} & 0,99 * *\end{array}$

(a)

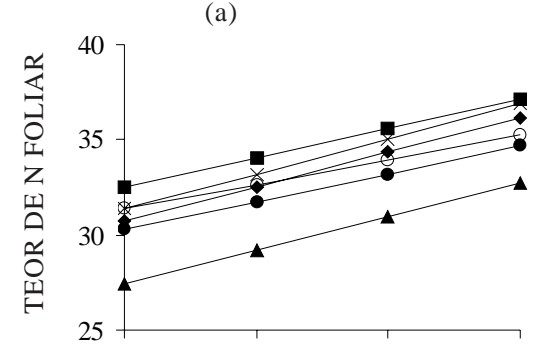

$\begin{array}{lll}\text { E1P1 } & \hat{Y}=62,50+0,024 X & 0,96 * * \\ \text { E1P2 } & \hat{Y}=60,46+0,041 X & 0,98 * * \\ \text { E1P3 } & \hat{Y}=59,44+0,034 X & 0,99 * * \\ \text { E2P1 } & \hat{Y}=58,87+0,030 X & 0,96 * * \\ \text { E2P2 } & \hat{Y}=58,85+0,048 X & 0,99 * * \\ \text { E2P3 } & \hat{Y}=60,01+0,025 X & 0,98 * *\end{array}$

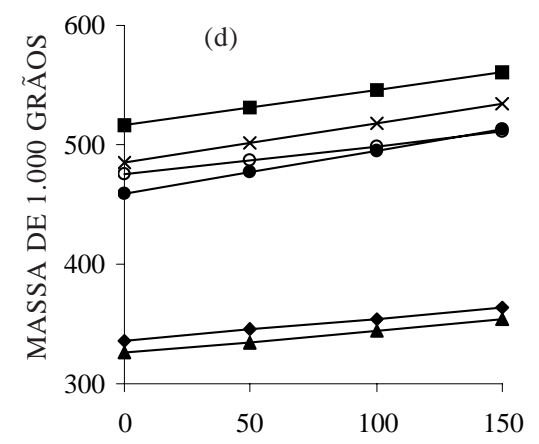

E1P1 $\hat{Y}=62,50+0,024 X$

E1P2 $\hat{Y}=60,46+0,041 X$

E1P3 $\hat{Y}=59,44+0,034 X$

E2P1 $\hat{Y}=58,87+0,030 X$

$\mathrm{E} 2 \mathrm{P} 3$
E2P2 $\hat{\mathrm{Y}}=58,85+0,048 \mathrm{X}$

$0,96 * *$
$0,98 * *$
$0,99 * *$
$0,96 * *$
$0,99 * *$
$0,98 * *$

(b)

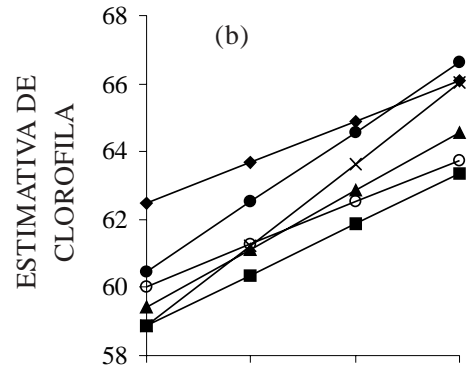

E1P1

E1P2

E1P3

E2P1

E2P2

$\mathrm{E} 2 \mathrm{P} 3$

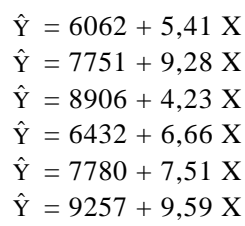

$0,99 * *$

$0,98 * *$

$0,99 * *$

$0,99 * *$

$0,94 * *$

$0,96 * *$

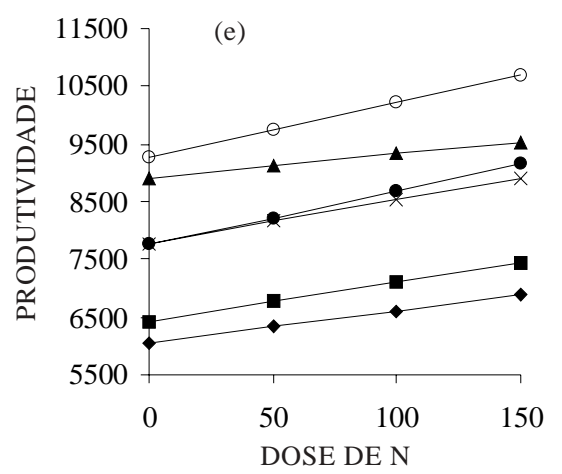

E1P1
E1P2
E1P3
E2P1
E2P2
E2P3

$\hat{\mathrm{Y}}=509,63+0,178 \mathrm{X}$

$\hat{\mathrm{Y}}=485,45+0,359 \mathrm{X}$

$\hat{\mathrm{Y}}=459,23+0,360 \mathrm{X}$

$\hat{Y}=516,65+0,228 X$

$\hat{Y}=484,78+0,328 X$

$\hat{\mathrm{Y}}=475,15+0,243 \mathrm{X}$

$0,95 * *$

$0,99 * *$

$0,94 * *$

$0,97 * *$

$0,98 * *$

$0,98 * *$

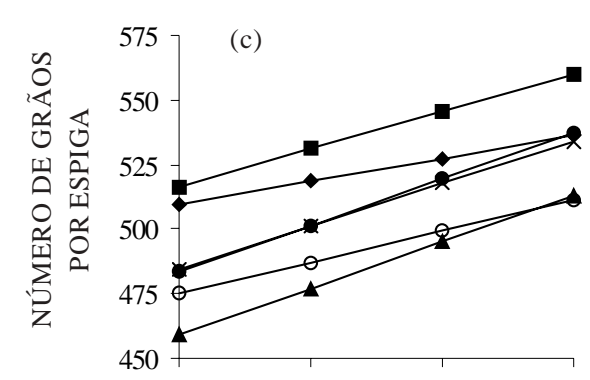

$\begin{array}{lll}\text { E1P1 } & \hat{\mathrm{Y}}=62,50+0,024 \mathrm{X} & 0,96^{* *} \\ \text { E1P2 } & \hat{\mathrm{Y}}=60,46+0,041 \mathrm{X} & 0,98^{* *} \\ \text { E1P3 } & \hat{\mathrm{Y}}=59,44+0,034 \mathrm{X} & 0,99^{* *} \\ \text { E2P1 } & \hat{\mathrm{Y}}=58,87+0,030 \mathrm{X} & 0,96^{* *} \\ \text { E2P2 } & \hat{\mathrm{Y}}=58,85+0,048 \mathrm{X} & 0,99^{* *} \\ \text { E2P3 } & \hat{\mathrm{Y}}=60,01+0,025 \mathrm{X} & 0,98^{* *}\end{array}$

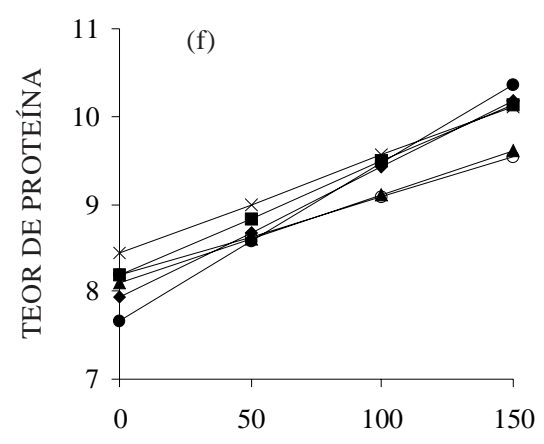

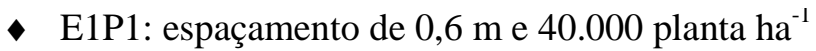

- E1P2: espaçamento de 0,6 m e 60.000 planta ha $^{-1}$

- E2P1: espaçamento de $0,8 \mathrm{~m}$ e 40.000 planta $^{-1}$

৯ E1P3: espaçamento de $0,6 \mathrm{~m}$ e 80.000 planta $^{-1}$

$X$ E2P2: espaçamento de $0,8 \mathrm{~m}$ e 60.000 planta $\mathrm{ha}^{-1}$

O E2P3: espaçamento de $0,8 \mathrm{~m}$ e 80.000 planta $^{-1}$

Figura 1. Teor de nitrogênio foliar (a); estimativa de clorofila (b); número de grãos por espiga (c); massa de $\mathbf{1 . 0 0 0}$ grãos (d); produtividade de grãos (e) e teor de proteína nos grãos (f) de milho submetido a diferentes arranjos populacionais e doses de nitrogênio. 
Anal isando as características genéticas do híbrido simples AG 9010, verificou-se, sob condições favoráveis de clima esolo, quea densidade populacional indicada variava de 60 a 80.000 plantas ha-1 ${ }^{-1}$ visto que quanto mais favoráveis eram as condições edafoclimáticas, maior seria a população necessária para maximizar a produtividade de grãos (Peixoto et al., 1997).

A adição de doses de nitrogênio também aumentou linearmente os val ores protéicos dos grãos (Figura 1f). Valois et al. (1983), avaliando seis densidades populacionais de milho, não detectaram variação em relação a esse componente. Paschoalik (1998), trabalhando com cinco híbridos eseteépocas de aplicação de nitrogênio, também verificou que a adubação não apresentou efeito nos teores de proteína nos grãos.

\section{CONCLUSÕES}

1. O aumento na doses de $\mathrm{N}$ em cobertura promoveu acréscimo linear no teor de $\mathrm{N}$ foliar, na estimativa do teor de clor ofila, no número de grãos por espiga, na massa de 1.000 grãos, na produtividade e no teor de proteína nos grãos da cultura do milho.

2. A maior produtividade de grãos foi obtida de acordo com as doses crescentes de $\mathrm{N}$ em cobertura juntamente com o espaçamento entre linhas de 0,80 me 80.000 plantas ha-1.

\section{AGRADE CI MENTOS}

À Fazenda de Ensino, Pesquisa e Produção, aos funcionários da FCAV/UNESP, campus de J aboticabal, pela área concedida para a instalação do experimento e auxílio nas atividades de campo e laboratório.

\section{LITE RATURA CITADA}

ANDRÉ, R.G.B. \& VOLPE, C.A. Dados meteorológicos de J aboticabal no Estado de São Paulo durante os anos de 1971 a 1980. J aboticabal, Faculdade de Ciências Agrárias e Veterinárias, 1982. (Boletim técnico)

ANDRIOLLI, I.\& CENTURION, J.F. Levantamento detal hado dos sol os da Facul dade de Ciências Agrárias eVeterinárias de J aboticabal. In: CONGRESSO BRASILEIRO DE CIÊNCIAS DO SOLO, 27., Brasília, 1999. Anais. Brasília, Sociedade Brasileira de Ciência do Solo, 1999. 32p. CDROOM.

ARGENTA， G.; SILVA，P.R.F.; BORTOLINI， C.G.; FORSTHOFER, E.L.; STRIEDER, M.L. \& STEFANI, G.F. Relação entre teor de clorofila extraível e leitura do clorofilômetro na fol ha de milho. In: CONGRESSO NACIONAL DE MILHO E SORGO, 23., U berlândia, 2000. Resumos. Uberlândia, ABMS, 2000b. p.197.
ARGENTA, G.; SILVA, P.R.F.; BORTOLINI, C.G.; STRIEDER, M.L. \& FORSTHOFER, E.L. Monitoramento do nível de nitrogênio na plantas de milho através do teor de clorofila avaliado pel o cl orofilômetro. In: CONGRESSO NACIONAL DE MILHO E SORGO, 23., Uberlândia., 2000. Resumos. Uberlândia, ABMS, 2000a. p.198.

BÜLL, L.T. Nutrição mineral do milho. In: BÜLL, L.T. \& CANTARELLA, H., eds, Cultura do milho: fatores que afetam a produtividade. Piracicaba, POTAF OS, 1993.p. 63145.

DOURADO NETO, D.; PALHARES, M.; VIEIRA, P.A.; MANFRON, P.A.; MEDEIROS, S.L.P. \& ROMANO, M.R. Efeito da população de plantas e do espaçamento sobre a produtividadedemilho. R. Bras. MilhoSorgo, 2:63-77, 2003.

DURIEX, R.P.; KAMPRATH, E.J. \& MOOL, R.H. Yield contribution of apical and subapical ears in prolific and nonprolific corn. Agron. J ., 85:606-610, 1993.

ESCOSTEGUY, P.A.V.; RIZZARDI, M.A. \& ARGENTA, G. Doses e épocas de aplicação de nitrogênio em cobertura na cultura do milho em duas épocas de semeadura. R. Bras. Ci. Solo, 21:71-77, 1997.

FANCELLI, A.L. Plantas alimentícias: guia para aula, estudoe discussão. Piracicaba: USP, ESALQ/CALQ, 1986. 131p.

FORNASIERI FILHO, D. A cultura do milho. J aboticabal, FUNEP, 1992.p.273.

MALAVOLTA, E. Avaliação do estado nutricional das plantas princípios e aplicações. Piracicaba, Associação Brasileira para Pesquisa de Potassa e do F osfato, 1987. p.201.

MELGAR, R.J .; SMITH, T.J .; CRAVO, M.S. \& SÁNCHEZ, P.A. Doses e épocas de aplicação de fertilizantes nitrogenado para milho em Latossolo da Amazônia Central. R. Bras. Ci. Solo, 15:289-296, 1991.

MINOLTA. Camera CO. Manual for chlorophyll meter SPAD 502. Osaka: Minolta, Radiometric I nstrumentes Divisions, 1989. p.22.

MOLIN, R. Espaçamento entrelinhas de semeadura na cultura de milho. Castro, Fundação $A B C$ para Assistência e Divulgação Técnica Agropecuária, 2000. p.1-2.

PASCHOALIK, H.N.S. Efeitos da época de aplicação de nitrogênio na produção, teor deóleo ena qualidade protéica de cultivares de milho (Zea mays L.) normal e QPM. J aboticabal, Universidade Estadual Paulista, 1998. p.107 (Tese de Doutorado)

PEIXOTO, C.M.; SILVA, P.R.F.; REZER, F. \& CARMONA, R.C. Produtividade de híbridos de mil ho em função da densidade de plantas, em dois níveis de manejo da água e da adubação. Pesq. Agropec. Gaúcha, 3:63-71, 1997.

PENARIOL, F.G.; FORNASIERI FILHO, D.; COICEV, L.; BORDIN, L. \& FARINELLI, R. Comportamento de cultivares de milho semeadas em diferentes espaçamentos entre linhas e densidades populacionais, na safrinha. R. Bras. Milho Sorgo, 2:52-60, 2003.

PEREIRA, R.S.B. Caracteres correlacionados com a produção e suas alterações no mel horamento genético do milho (Zea mays L.). Pesq. Agropec. Bras, 26:745-751, 1991. 
PIEKIELEK, W.P.; FOX, R.H.; TOTH, J .D. \& MACNEAL, K.E.. Use of a chlorophyll meter at the early dent stage of corn to evaluante N sufficiency. Agron. J , 87:403-408, 1995.

RAIJ , B, van; CANTARELLA, H.; QUAGGIO, J .A. \& FURLANI, A.M.C. Recomendações de adubação e calagem para o estado de São Paulo. 2.ed. Campinas, Instituto Agronômico de Campinas, 1996. p.60-61. (Boletim, 100)

RAIJ , B. van \& QUAGGIO, J.A. Métodos de análise de solo para fins de fertilidade. Campinas, Instituto Agronômico de Campinas, 1983. 31p. (Boletim Técnico, 81)

REZENDE, S.G.; VON PINHO, R.G. \& VASCONCELOS, R.C. Influência do espaçamento entre linhas e da densidade de plantio no desempenho de cultivares de milho. R. Bras. Milho Sorgo, 2:34-42, 2003.
SANGOI, I.; ENDER, M. \& GUIDOLIN, H. F. Incremento da densidade de plantas, uma alternativa para aumentar o rendimento de grãos de milho em regiões de curta estação de crescimento. R. Rural, 30:23-29, 2000.

SOUZA, L.C.F.; GONÇALVES, M.C.; SOBRINHO, T.A.; FEDATTO, E.; ZANON, G.D. \& HASEGAWA, E.K.B. Culturas antecessoras e adubação nitrogenada na produtividade de mil ho em plantio direto irrigado. R. Bras. Milho Sorgo, 2:55-62, 2003.

ULGER, A.C.; BECKER, A.C. \& KANT, G. Response of varions maiz imbred lineand hybrids to increasing rates of nitrogen fertilizer. J . Agron. Crop Sci., 159:157-163, 1987.

VALOIS, A.C.C.; TOSELLO, G.A.; ZANOTTO, M.D. \& SCHIMIT, G.S. Análise de qualidade de grãos de milho. Pesq. Agropec. Bras., 18:771-778, 1983. 
J osé Pedro Ribeiro do Amaral Filho et al. 